\title{
Research on Cost Information Sharing and Channel Choice in a Dual-Channel Supply Chain
}

\author{
Huihui Liu, ${ }^{1}$ Shuguang Sun, ${ }^{2}$ Ming Lei, ${ }^{3}$ G. Keong Leong, ${ }^{4}$ and Honghui Deng ${ }^{5}$ \\ ${ }^{1}$ Academy of Chinese Energy Strategy, China University of Petroleum, Beijing 102249, China \\ ${ }^{2}$ China Merchants Securities, Beijing 100013, China \\ ${ }^{3}$ Guanghua School of Management, Peking University, Beijing 100871, China \\ ${ }^{4}$ College of Business Administration and Public Policy, California State University, Dominguez Hills, \\ Carson, CA 90747, USA \\ ${ }^{5}$ Lee Business School, University of Nevada, Las Vegas, NV 89154, USA \\ Correspondence should be addressed to G. Keong Leong; gkleong@csudh.edu
}

Received 16 November 2015; Revised 30 March 2016; Accepted 31 March 2016

Academic Editor: Vladimir Turetsky

Copyright ( 2016 Huihui Liu et al. This is an open access article distributed under the Creative Commons Attribution License, which permits unrestricted use, distribution, and reproduction in any medium, provided the original work is properly cited.

\begin{abstract}
Many studies examine information sharing in an uncertain demand environment in a supply chain. However there is little literature on cost information sharing in a dual-channel structure consisting of a retail channel and a direct sales channel. Assuming that the retail sale cost and direct sale cost are random variables with a general distribution, the paper investigates the retailer's choice on cost information sharing in a Bertrand competition model. Based on the equilibrium outcome of information sharing, the manufacturer's channel choice is discussed in detail. Our paper provides several interesting conclusions. In both single- and dualchannel structures, the retailer has little motivation to share its private cost information which is verified to be valuable for the manufacturer. When the cost correlation between the two channels increases, our analyses show that the manufacturer's profit improves. However, when channel choice is involved, the value of information could play a different role. The paper finds that a dual-channel structure can benefit the manufacturer only when the cost correlation is sufficiently low. In addition, if the cost correlation is weak, the cost fluctuation will bring out the advantage of a dual-channel structure and adding a new direct channel will help in risk pooling.
\end{abstract}

\section{Introduction}

With the rapid development of e-commerce and third-party logistics, many manufacturers set up a direct sales channel besides an existing retail channel. As such the dual-channel structure is becoming more common in the business world. For a supply chain with one retail channel, introducing a direct channel will have a big impact on both manufacturers and retailers, since the retail and direct channels compete in the same market. How to choose the optimal sales channel structure becomes a key question facing manufacturers looking to maximize profits.

In business reality, because of various uncontrollable factors, sale costs are usually uncertain and private for firms in a supply chain. Take the retailer Best Buy as an example; the income from maintenance service is an important part of operating profit, and the cost generated is always uncertain and held privately by Best Buy [1]. In addition, we find that many franchisees often conceal cost information such as sales cost from franchisors in the contract [2]. Since cost is a crucial factor in a firm's profit performance, the fluctuation in cost should not be ignored. In a supply chain, cost uncertainty influences directly pricing decision, products sales amount in specific sale channel, and even cooperation between upstream and downstream firms. As such cost information sharing becomes an important issue for firms in a supply chain.

The two issues of channel choice and cost information sharing are closely related. On one hand, once the retailer chooses to share cost information, which will affect the distribution of cost information among the supply chain firms, the manufacturer has to examine the channel choice 
again. On the other hand, channel structure has a direct influence on the retailer. The manufacturer direct sales cost is also uncertain, and usually correlated with the sales cost in a retail channel since the same products are sold in the market. Therefore, once a direct channel is added, the retailer has to rethink the sharing choice. Another important concern is the process of comparing the value of cost information. The value is one thing in a certain channel structure, but may be another thing when comparing different channel structures in making a channel choice.

Due to the popularity of the dual-channel structure, many studies investigate whether a manufacturer should open up a direct channel (Park and Keh [3], Chiang et al. [4], Liu and Zhang [5], Dumrongsiri et al. [6], Cai [7], and Yoo and Lee [8]). However, in the situation with cost uncertainty, the analysis of channel choice is still lacking. In addition, in a dual-channel structure, there is little literature on cost information sharing involving cost uncertainty. With the above motivation, our paper focuses on a retailer's choice on cost information sharing and a manufacturer's channel choice in a dual-channel supply chain with cost uncertainty.

The objective of our paper is to provide answers to the following questions. (1) Is a retailer willing to share cost information with the upstream manufacturer in a dualchannel structure? (2) Based on the analysis in information sharing, how do cost uncertainties in the two channels affect the manufacturer's channel choice? In a dual-channel supply chain consisting of a manufacturer and a retailer, the paper establishes a Stackelberg game and studies the retailer's information sharing choice. By comparing the manufacturer's profits in the dual-channel and single-channel structures, the conditions under which a direct channel should be added are provided.

\section{Literature Review}

Recently, the issue of sharing uncertain information in supply chain is a hot topic because of its impact on profitability and how companies organize their distribution channels. According to Li's [9] classification on information value, uncertainty could be divided into two groups: common value and private value. Among all the uncertainty sources, demand and cost are the most familiar ones, which belong to common value and private value, respectively.

In a review of the information sharing literature, most related studies focus on whether a retailer shares its private market demand information [10-15]. With fluctuating demand, Yue and Liu [16] examine vertical information sharing and channel choice in supply chain with one retailer. Lei et al. [17] extend their study to a situation with multiple retailers and also examine horizontal information sharing between retailers. To reduce the influence of uncertainties, Ryu et al. [18] investigate two types of information sharing methods to clarify their control characteristics; one is based on planned demand and the other on forecasted demand. In the above studies, cost uncertainty is not involved.
In the literature related with cost uncertainty, several studies examine sharing behavior in an oligopoly situation when there is firm-specific cost uncertainty. In a Cournot competition, Li's [9] research examines information sharing in both demand and cost. Wu et al. [19] introduce capacity upper limit and discusses partial sharing behavior in a duopoly. Also, some researchers focus on cost information sharing in a supply chain. For example, in Yao et al. [20], two retailers add value to goods by improving their service after wholesaling from a manufacturer, and the coefficient in the cost of adding value is uncertain. All the above papers only consider a single-channel structure in a supply chain.

Research in a dual-channel supply chain structure is still lacking. Mukhopadhyay et al. [21] and Cao et al. [22] examine cost information sharing in a dual-channel supply chain. Mukhopadhyay et al. [21] extend Yao et al's [20] study to a dual-channel setting. The cost coefficient of value-added service is assumed to be unknown by others. The assumption is that a retailer's cost is either high or low, and a signaling game is carried out with respect to the retailer's cost. From the perspective of supply chain coordination, this paper only maximizes the manufacturer's profit and derives the optimal pricing decision.

Our paper differs from previous research in the following ways. First, we assume that uncertainty comes from sale cost itself and is a random variable with a general distribution. Second, since the manufacturer bears the cost when selling in a direct channel, the direct sales cost is assumed uncertain too, and we focus on the correlation between costs in the two channels. Finally, based on the results of information sharing, the manufacturer's channel choice is discussed and the effect of cost fluctuation is explored in detail.

The rest of the paper is organized as follows. Section 3 provides a model framework with basic model settings provided. In Section 4, the retailer's decision on whether to share information is examined both in a dual-channel structure and single-channel structure. We discuss the manufacturer's decision on channel structure in Section 5. Finally, in Section 6, we provide concluding remarks.

\section{Model Framework}

In a supply chain consisting of one manufacturer and one retailer, the manufacturer wholesales products to the retailer, which sells them to consumers at the retail price. If a direct channel is added, the manufacturer also markets directly to consumers at the direct sales price. In a dual-channel structure, the two channels compete on price.

Several key assumptions are made which are consistent with previous studies [3, 17, 23, 24].

(1) The manufacturer only provides base products to the retailer and the direct channel. Due to geographic factors and services, the products sold by the two channels are imperfect substitutes.

(2) The direct sale price is higher than the wholesale price, to avoid the retailer purchasing from the direct channel. 
(3) Fixed costs are not considered.

To clearly differentiate the different channels and scenarios, we use subscripts $\mathrm{d}$ and $\mathrm{r}$ to denote direct channel and retail channel, and superscripts $S$ and NS to represent sharing information and nonsharing information. To facilitate understanding of the model, the symbols used and their corresponding definitions are shown in Abbreviations section.

Similar to Yue and Liu's [16] study, demand functions in the direct channel and retail channel are set as $D_{\mathrm{d}}=\lambda a-$ $b_{1} p_{\mathrm{d}}+e p_{\mathrm{r}}$ and $D_{\mathrm{r}}=(1-\lambda) a-b_{2} p_{\mathrm{r}}+e p_{\mathrm{d}}$. We define $a$ as the basic demand (i.e., potential demand if products are free of charge). Here $\lambda$ represents the proportion of basic market demand for the direct channel, exclusive of the price factor. $\lambda$ indicates the consumer's preference and captures the absolute difference in demands between retail and direct channels. A higher value of $\lambda$ means a larger preference for the direct channel, and consequently a high proportion of basic market demand will be in the direct channel. For example, if the proportion of consumers with a preference for online purchase in a community is very large, then $\lambda$ is likely to be high. $\lambda$ is assumed to be an exogenous variable ( $[16,25-$ 28]). Cross-price sensitivity $e$ shows the cross effect of price competition between channels. Generally we have $b_{1}>e$ and $b_{2}>e$, which means that "own price sensitivity" is greater than "cross-price sensitivity."

In a single-channel structure where the manufacturer does not add a direct channel, the market demand function is $D=a-b p_{\mathrm{r}}$.

To investigate the effect of cost fluctuation, we use Li's [29] assumption for cost setting. We assume that they are random variables with identical distribution and meet the following conditions:

$$
\begin{gathered}
E\left[c_{\mathrm{d}}\right]=E\left[c_{\mathrm{r}}\right]=0, \\
\operatorname{Var}\left[c_{\mathrm{d}}\right]=\operatorname{Var}\left[c_{\mathrm{r}}\right]=\sigma^{2}, \\
E\left[c_{\mathrm{d}} \mid c_{\mathrm{r}}\right]=\alpha_{1}+\alpha_{2} c_{\mathrm{r}}, \\
E\left[c_{\mathrm{r}} \mid c_{\mathrm{d}}\right]=\beta_{1}+\beta_{2} c_{\mathrm{d}} .
\end{gathered}
$$

Here $\alpha_{1}, \alpha_{2}$ and $\beta_{1}, \beta_{2}$ are assumed to be nonnegative constants, which indicates that the manufacturer's direct cost and the retailer's retail cost are positively related, which is consistent with what happens in practice. The setting of $c_{\mathrm{d}}$ and $c_{\mathrm{r}}$ includes a series of distribution, such as a normal distribution function. By referring to $\mathrm{Li}[9$, Lemma 3 ], we have the following lemma used in solving our model.

Lemma 1. $E\left[c_{r} \mid c_{d}\right]=\rho c_{d}, E\left[c_{d} \mid c_{r}\right]=\rho c_{r}$, where $\rho$ is the correlation coefficient between $c_{d}$ and $c_{r}$, and $0<\rho<1$. (See the Appendix for proof.)

Next the paper examines the retailer's information sharing choice in a dual-channel structure and single-channel structure. Based on the obtained results, the manufacturer's channel choice is studied.

\section{Cost Information Sharing}

4.1. Dual-Channel Structure. In a dual-channel structure, the order of events is as follows. First, the manufacturer decides the wholesale price and direct sales price; then the retailer chooses a retail price. Note that the retailer can deduce the manufacturer's cost information (the direct sales cost), after observing the wholesale price and direct sales price, which are usually made by the manufacturer based on how much it costs. Then the manufacturer's direct sales cost will be leaked once the wholesale price and direct sales price are announced. Therefore we examine the information sharing choice only on the retailer's private information.

Two situations with and without the retailer's information sharing will be discussed. Then we compare the retailer's profits in these two situations, from which the retailer's choice on information sharing will be obtained.

4.1.1. Without Retailer's Sharing Cost Information. We solve the dynamic game by using backward induction. In stage two, the retailer decides the retail price $p_{\mathrm{r}}$ given the manufacturer's wholesale price $\omega$ and direct sales price $p_{\mathrm{d}}$. The retailer's conditional expected profit is expressed as

$$
E\left[\pi_{\mathrm{r}} \mid c_{\mathrm{d}}, c_{\mathrm{r}}\right]=\left(p_{\mathrm{r}}-\omega-c_{\mathrm{r}}\right)\left((1-\lambda) a-b_{2} p_{\mathrm{r}}+e p_{\mathrm{d}}\right) .
$$

According to the first-order condition, we obtain the retailer's best response function of retail price: $p_{\mathrm{r}}=(a(1-$ $\left.\lambda)+\left(\omega+c_{\mathrm{r}}\right) b_{2}+e p_{\mathrm{d}}\right) / 2 b_{2}$.

In stage one, the manufacturer sets wholesale price and direct sales price and does not own the retailer's private information. The manufacturer's conditional expected profit is expressed as

$$
\begin{aligned}
E\left[\pi_{\mathrm{m}} \mid c_{\mathrm{d}}\right]= & \left(p_{\mathrm{d}}-c_{\mathrm{d}}\right)\left(\lambda a-b_{1} p_{\mathrm{d}}+e E\left[p_{\mathrm{r}} \mid c_{\mathrm{d}}\right]\right) \\
& +\omega\left((1-\lambda) a-b_{2} E\left[p_{\mathrm{r}} \mid c_{\mathrm{d}}\right]+e p_{\mathrm{d}}\right)
\end{aligned}
$$

After substituting the retailer's response function into the manufacturer's profit function, we can get the firstorder condition with respect to wholesale price $\omega$ and the direct sales price $p_{\mathrm{d}}$. We summarize the unique equilibrium solution in Proposition 2.

Proposition 2. In a dual-channel structure without the retailer's information sharing, one gets the following equilibrium solution (please see the Appendix for proof).

The wholesale price is $\omega^{*}=\left(-e\left(a \lambda+e \rho c_{d}\right)+b_{1}(a(-1+\right.$ $\left.\left.\lambda)+\rho b_{2} c_{d}\right)\right) / 2\left(e^{2}-b_{1} b_{2}\right)$, and the direct sales price is $p_{d}^{*}=$ $\left(e\left(a(-1+\lambda)+e c_{d}\right)-b_{2}\left(a \lambda+b_{1} c_{d}\right)\right) / 2\left(e^{2}-b_{1} b_{2}\right)$.

The manufacturer's conditional expected profit is 


$$
\begin{aligned}
& E\left[\pi_{m-B}^{* N S} \mid c_{d}\right] \\
& =-\frac{\rho^{2} b_{1} b_{2}^{3} c_{d}^{2}+e^{2}\left(a-a \lambda+e c_{d}\right)^{2}-b_{2}\left(a(-1+\lambda)-e c_{d}\right)\left(b_{1}\left(a-a \lambda-3 e c_{d}\right)+2 e\left(2 a \lambda+e \rho c_{d}\right)\right)+b_{2}^{2}\left(2 a^{2} \lambda^{2}-e^{2} \rho^{2} c_{d}^{2}+2 b_{1}^{2} c_{d}^{2}-2 b_{1} c_{d}\left(a(\rho+2 \lambda-\rho \lambda)+e \rho c_{d}\right)\right)}{8 b_{2}\left(e^{2}-b_{1} b_{2}\right)},
\end{aligned}
$$

and the manufacturer's expected profit is

$$
\begin{aligned}
& \Pi_{m-B}^{* N S} \\
& =\frac{\rho^{2} b_{1} b_{2}^{3} \sigma^{2}+e^{2}\left((a-a \lambda)^{2}+e^{2} \sigma^{2}\right)+b_{2}\left((a-a \lambda)^{2} b_{1}-3 b_{1} e^{2} \sigma^{2}+4 e a^{2}\left(\lambda-\lambda^{2}\right)+2 \rho e^{3} \sigma^{2}\right)+b_{2}^{2}\left(2 a^{2} \lambda^{2}-e^{2} \rho^{2} \sigma^{2}+2 b_{1}^{2} \sigma^{2}-2 b_{1} e \rho \sigma^{2}\right)}{8 b_{2}\left(b_{1} b_{2}-e^{2}\right)} .
\end{aligned}
$$

For the retailer, the equilibrium retail price is

$$
p_{r}^{*}=\frac{e^{2}\left(a-a \lambda+e c_{d}\right)+b_{1} b_{2}^{2}\left(\rho c_{d}-2 c_{r}\right)-b_{2}\left(b_{1}\left(3 a-3 a \lambda+e c_{d}\right)+e\left(2 a \lambda+e \rho c_{d}-2 e c_{r}\right)\right)}{4 b_{2}\left(e^{2}-b_{1} b_{2}\right)} .
$$

The conditional expected profit is $E\left[\pi_{r B}^{* N S} \mid c_{d}, c_{r}\right]=(a-a \lambda+$ $\left.\left(e+\rho b_{2}\right) c_{d}-2 b_{2} c_{r}\right)^{2} / 16 b_{2}$, and the expected profit is $\Pi_{r B}^{* N S}=$ $a^{2}(1-\lambda)^{2} / 16 b_{2}+\left(\sigma^{2} / 16 b_{2}\right)\left(\left(e+\rho b_{2}\right)^{2}+4 b_{2}^{2}-4\left(e+\rho b_{2}\right) b_{2} \rho\right)$.

In Proposition 2, it is obvious that the manufacturer's wholesale price and direct sales price in the equilibrium are linear functions of the direct sales cost, which means the manufacturer's decisions contain the information about its cost in the direct channel. Because the manufacturer is the Stackelberg game leader, its pricing decision will be observed by the retailer just before the retail pricing is set. Thus, the manufacturer's cost information in the direct channel will be leaked indirectly to the retailer through the wholesale price (or direct sales price).

4.1.2. With Retailer's Sharing Cost Information. Next, we consider the situation in which the retailer shares the cost information with the manufacturer. In stage two, the retailer's best response function of retail price is the same as that without information sharing: $p_{\mathrm{r}}=\left(a(1-\lambda)+\left(\omega+c_{\mathrm{r}}\right) b_{2}+\right.$ $\left.e p_{\mathrm{d}}\right) / 2 b_{2}$.
In stage one, the manufacturer gets the retailer's information on retail cost, so its conditional expected profit function is

$$
\begin{aligned}
E\left[\pi_{\mathrm{m}} \mid c_{\mathrm{d}}, c_{\mathrm{r}}\right]= & \left(p_{\mathrm{d}}-c_{\mathrm{d}}\right)\left(\lambda a-b_{1} p_{\mathrm{d}}+e p_{\mathrm{r}}\right) \\
& +\omega\left((1-\lambda) a-b_{2} p_{\mathrm{r}}+e p_{\mathrm{d}}\right) .
\end{aligned}
$$

By using the similar method in the situation without information sharing, we can calculate the manufacturer's optimal wholesale price and direct sale price. We summarize the unique equilibrium solution in Proposition 3.

Proposition 3. In a dual-channel structure with retailer cost information sharing, one gets the following equilibrium solution (please see the Appendix for proof).

The wholesale price is $\omega^{*}=\left(-e\left(a \lambda+e c_{r}\right)+b_{1}(a(-1+\lambda)+\right.$ $\left.\left.b_{2} c_{r}\right)\right) / 2\left(e^{2}-b_{1} b_{2}\right)$, and the direct sale price is $p_{d}^{*}=(e(a(-1+$ $\left.\left.\lambda)+e c_{d}\right)-b_{2}\left(a \lambda+b_{1} c_{d}\right)\right) / 2\left(e^{2}-b_{1} b_{2}\right)$.

The manufacturer's conditional expected profit is

$$
\begin{aligned}
& E\left[\pi_{m-B}^{* S} \mid c_{r}, c_{d}\right] \\
& =-\frac{e^{2}\left(a-a \lambda+e c_{d}\right)^{2}+b_{1} b_{2}^{3} c_{r}^{2}-b_{2}\left(a(-1+\lambda)-e c_{d}\right)\left(b_{1}\left(a-a \lambda-3 e c_{d}\right)+2 e\left(2 a \lambda+e c_{r}\right)\right)+b_{2}^{2}\left(2 a^{2} \lambda^{2}+2 b_{1}^{2} c_{d}^{2}-e^{2} c_{r}^{2}-2 b_{1}\left(-a(-1+\lambda) c_{r}+c_{d}\left(2 a \lambda+e c_{r}\right)\right)\right)}{8 b_{2}\left(e^{2}-b_{1} b_{2}\right)},
\end{aligned}
$$

and the manufacturer's expected profit is

$$
\begin{aligned}
& \Pi_{m \_B}^{* S} \\
& =\frac{e^{2}\left((a-a \lambda)^{2}+e^{2} \sigma^{2}\right)+b_{1} b_{2}^{3} \sigma^{2}+b_{2}\left((a-a \lambda)^{2} b_{1}-3 b_{1} e^{2} \sigma^{2}+4 e a^{2}\left(\lambda-\lambda^{2}\right)+2 \rho e^{3} \sigma^{2}\right)+b_{2}^{2}\left(2 a^{2} \lambda^{2}+2 b_{1}^{2} \sigma^{2}-e^{2} \sigma^{2}-2 b_{1} e \rho \sigma^{2}\right)}{8 b_{2}\left(b_{1} b_{2}-e^{2}\right)} .
\end{aligned}
$$


For the retailer, the equilibrium retail price is

$$
p_{r}^{*}=\frac{e^{2}\left(a-a \lambda+e c_{d}\right)-b_{1} b_{2}^{2} c_{r}+b_{2}\left(b_{1}\left(3 a(-1+\lambda)-e c_{d}\right)+e\left(-2 a \lambda+e c_{r}\right)\right)}{4 b_{2}\left(e^{2}-b_{1} b_{2}\right)} .
$$

The conditional expected profit is $E\left[\pi_{r B}^{* S} \mid c_{r}, c_{d}\right]=(a(-1+$ $\left.\lambda)-e c_{d}+b_{2} c_{r}\right)^{2} / 16 b_{2}$, and the expected profit is $\Pi_{r-B}^{* S}=a^{2}(1-$ $\lambda)^{2} / 16 b_{2}+\left(\sigma^{2} / 16 b_{2}\right)\left(e^{2}+b_{2}^{2}-2 e b_{2} \rho\right)$.

In Proposition 3, which is similar to Proposition 2, the manufacturer's wholesale price and direct sales price in the equilibrium contain the information about its cost in the direct channel, and will be observed by the retailer before the retail pricing is set. Therefore, the manufacturer's cost information in the direct channel will be leaked indirectly to the retailer.

Compared with the situation without retailer's sharing cost information, the direct sales price remains the same because the direct price is only related to direct costs $c_{\mathrm{d}}, b_{1}$, $b_{2}$, and $e$, rather than the retail price $c_{\mathrm{r}}$. The wholesale prices are different, $\omega^{* S}-\omega^{* N S}=\left(E\left[c_{\mathrm{r}} \mid c_{\mathrm{d}}\right]-c_{\mathrm{r}}\right) / 2$, and the changing direction depends on the relative value between the conditional expectation of the retailer's cost $E\left[c_{\mathrm{r}} \mid c_{\mathrm{d}}\right]$ and the actual cost $c_{\mathrm{r}}$.

4.1.3. Decision on Information Sharing. Based on the above analysis with and without the retailer's information sharing, the paper further studies the retailer's information sharing decision. By comparing the manufacturer's and retailer's expected profits with and without cost information sharing, Theorem 4 is obtained as follows.

Theorem 4. In a dual-channel structure, cost information sharing is beneficial for the manufacturer but not for the retailer. So the manufacturer expects the retailer to share cost information but the retailer tends not to want to do so (please see the Appendix for proof).

The conclusion in Theorem 4 is in accordance with our intuition. Due to information leakage on the manufacturer's direct sales cost, the retailer's cost information becomes the only source of uncertainty. Therefore, the manufacturer is in a passive position of cost information. Although the manufacturer can speculate the retailer's cost information through direct sale cost information: $E\left[c_{\mathrm{r}} \mid c_{\mathrm{d}}\right]=\rho c_{\mathrm{d}}$, it is only a part of the cost information $c_{\mathrm{r}}$ that can be obtained. When the degree of correlation between $c_{\mathrm{d}}$ and $c_{\mathrm{r}}$ reduces, which means a smaller $\rho$, the manufacturer has less access to the retailer's cost information. Once the retailer agrees to share information, the manufacturer will improve its weak position and work out a pricing decision that conforms to its own best interest and subsequently increases its total profit.

From the proof in Theorem 4, we find that when the retailer chooses to share information, the added profit to the manufacturer is $V_{\mathrm{m}}=\left(1-\rho^{2}\right) \sigma^{2} b_{2} / 8$; it is clear that the lower $\rho$ is, the higher $V_{\mathrm{m}}$ is. As such, when the correlation between costs in the two channels is low, the retailer's information sharing will be quite valuable for the manufacturer. With retailer's information sharing, the manufacturer's profit will increase substantially.

For the retailer, cost information sharing can have a negative effect on its profit. Before sharing cost information, the retailer enjoys an advantage in information asymmetry and obtains higher profit. After information sharing, the manufacturer gets a more comprehensive understanding of the retailer's cost and then makes targeted pricing decisions, which is bad for the retailer. The profit loss of the retailer caused by cost information sharing is $V_{\mathrm{r}}=-3\left(1-\rho^{2}\right) \sigma^{2} b_{2} / 16$.

It is obvious that, before sharing cost information, if the manufacturer's estimation on retail cost, $\left(E\left[\begin{array}{c|c}c_{\mathrm{r}} & c_{\mathrm{d}}\end{array}\right]\right)$, is greater than the real cost $c_{\mathrm{r}}$, then the manufacturer will decide on a lower wholesale price, which will enable the retailer to gain additional profit. If $E\left[c_{\mathrm{r}} \mid c_{\mathrm{d}}\right]$ is less than $c_{r}$, then the manufacturer will decide on a higher wholesale price, which will make the retailer suffer a loss. However, the chance that $E\left[c_{\mathrm{r}} \mid c_{\mathrm{d}}\right]$ is higher than $c_{\mathrm{r}}$ is quite small, because $c_{\mathrm{r}}$ and $c_{\mathrm{d}}$ are identically distributed. So, in general, the retailer's expected profit will decrease after cost information sharing.

4.2. Single-Channel Structure. To analyze the manufacturer's choice on adding a direct channel, the paper next studies the single-channel structure. The assumption is that although the manufacturer does not have a direct channel, it is considering the option to open one. In reality, manufacturers usually review channel needs and conduct market surveys in advance. As such the manufacturer has a good understanding of its own direct sales cost. In the first stage of the Stackelberg game, the manufacturer will decide the wholesale price. In making pricing decisions, the manufacturer will use its own direct sales cost to forecast the retailer's sales cost. This indicates that the wholesale price still contains the manufacturer's cost information, which will be leaked eventually to the retailer.

Using a similar method to that in the dual-channel structure, we discuss two situations without and with the retailer's information sharing. Then the retailer's sharing decision is examined.

4.2.1. Without Retailer Sharing Cost Information. In the first stage, the manufacturer will decide the wholesale price without knowing the retailer's private information. In the second stage, the retailer will set the retail price based on the information in the two channels. 
The retailer's conditional expected profit function is expressed as

$$
E\left[\pi_{\mathrm{r}} \mid c_{\mathrm{d}}, c_{\mathrm{r}}\right]=\left(p_{\mathrm{r}}-\omega-c_{\mathrm{r}}\right)\left((1-\lambda) a-b_{2} p_{\mathrm{r}}+e p_{\mathrm{d}}\right) .
$$

According to the first-order condition, we obtain the retailer's best response function on retail price $p_{\mathrm{r}}=(a)(1-$ $\left.\lambda)+\left(\omega+c_{\mathrm{r}}\right) b_{2}+e p_{\mathrm{d}}\right) / 2 b_{2}$.

In the first stage, the manufacturer chooses the optimal wholesale price $\omega$, to maximize the conditional expected profit:

$$
\begin{aligned}
E\left[\pi_{\mathrm{m}} \mid c_{\mathrm{d}}\right] & =E\left[\frac{1}{2} \omega\left(a-b \omega-b c_{\mathrm{r}}\right) \mid c_{\mathrm{d}}\right] \\
& =\frac{1}{2} \omega\left(a-b \omega-b \rho c_{\mathrm{d}}\right) .
\end{aligned}
$$

After substituting the retailer's response function into the manufacturer's profit function, we take the first-order derivative with respect to the wholesale price. By solving $\partial E\left[\pi_{\mathrm{m}} \mid c_{\mathrm{d}}\right] / \partial \omega=0$ we obtain the unique equilibrium solution shown in Proposition 5.

Proposition 5. In the single-channel structure without the retailer's information sharing, one gets the following equilibrium solution.

The wholesale price is $\omega^{*}=\left(a-b \rho c_{d}\right) / 2 b$, and the manufacturer's conditional expected profit is $E\left[\pi_{m \_R}^{* N S} \mid c_{d}\right]=$ $\left(a-b \rho c_{d}\right)^{2} / 8 b$, and its expected profit is $\Pi_{m-R}^{* N S}=\left(a^{2}+\right.$ $\left.b^{2} \rho^{2} \sigma^{2}\right) / 8 b$.

For the retailer, the equilibrium retail price is $p_{r}^{*}=(3 a-$ $\left.b \rho c_{d}+2 b c_{r}\right) / 4 b$. Its conditional expected profit is $E\left[\pi_{r-R}^{* N S}\right.$ । $\left.c_{r}, c_{d}\right]=\left(a+b \rho c_{d}-2 b c_{r}\right)^{2} / 16 b$, and the expected profit is $\Pi_{r_{-} R}^{* N S}=\left(a^{2}+\left(4-3 \rho^{2}\right) b^{2} \sigma^{2}\right) / 16 b$.

4.2.2. With Retailer Sharing Cost Information. In the second stage, the retailer's conditional expected profit function is still $E\left[\pi_{\mathrm{r}} \mid c_{\mathrm{d}}, c_{\mathrm{r}}\right]=\left(p_{\mathrm{r}}-\omega-c_{\mathrm{r}}\right)\left((1-\lambda) a-b_{2} p_{\mathrm{r}}+e p_{\mathrm{d}}\right)$, and its price response function remains as $p_{\mathrm{r}}=\left(a(1-\lambda)+\left(\omega+c_{\mathrm{r}}\right) b_{2}+\right.$ $\left.e p_{\mathrm{d}}\right) / 2 b_{2}$.

In the first stage, after substituting the retailer's retail price response function into the manufacturer's profit function, the manufacturer's conditional expected profit becomes $E\left[\pi_{\mathrm{m}} \mid\right.$ $\left.c_{\mathrm{d}}, c_{\mathrm{r}}\right]=E\left[(1 / 2) \omega\left(a-b \omega-b c_{\mathrm{r}}\right) \mid c_{\mathrm{d}}, c_{\mathrm{r}}\right]=(1 / 2) \omega\left(a-b \omega-b c_{\mathrm{r}}\right)$.

By taking the first-order derivative with respect to the wholesale price and solving $\partial E\left[\pi_{\mathrm{m}} \mid c_{\mathrm{d}}\right] / \partial \omega=0$, we obtain the unique equilibrium solution shown in Proposition 6.

Proposition 6. In a single-channel structure with the retailer sharing information, one gets the following equilibrium solution.

The wholesale price is $\omega^{*}=\left(a-b c_{r}\right) / 2 b$, the manufacturer's conditional expected profit is $\Pi_{m, R}^{* S}=\left(a-b c_{r}\right)^{2} / 8 b$, and its expected profit is $\Pi_{m R}^{* S}=\left(a^{2}+b^{2} \sigma^{2}\right) / 8 b$.

For the retailer, the equilibrium retail price is $p_{r}^{*}=(3 a+$ $\left.b c_{r}\right) / 4 b$, its conditional expected profit is $E\left[\pi_{r-R}^{* S} \mid c_{d}, c_{r}\right]=(a-$ $\left.b c_{r}\right)^{2} / 16 b$, and the expected profit is $\Pi_{r-R}^{* S}=\left(a^{2}+b^{2} \sigma^{2}\right) / 16 b$.
4.2.3. Decision on Information Sharing. Based on the above analysis with or without retailer information sharing, we further study the retailer's sharing decision. By comparing the manufacturer and retailer's expected profits with and without information sharing, Theorem 7 is obtained as follows.

Theorem 7. In a single-channel structure, the manufacturer is better off with the retailer's information sharing but the retailer is not willing to share information (please see the Appendix for proof).

One observes that when channel structure changes, the information sharing equilibrium outcome does not change. Once the retailer chooses to share information, it will suffer a profit loss of $3 b\left(1-\rho^{2}\right) \sigma^{2} / 16$, while the manufacturer's profit increases $b\left(1-\rho^{2}\right) \sigma^{2} / 8$. The reason is similar to that for the dual-channel structure.

\section{The Manufacturer's Channel Choice}

In both the dual-channel and single-channel structures, the equilibrium outcome is that the retailer tends not to share private information under the condition of cost uncertainty. So, in an environment without market contracts, there is no information sharing between firms in the supply chain. However, cooperation contract is beyond the scope of our research. Based on the retailer's choices in an open market environment, the paper discusses the issue of channel choice with cost uncertainty.

5.1. Profit Comparisons. By comparing the expected equilibrium profits in different channel structure without the retailer's sharing, the condition under which the dualchannel structure dominates can be obtained. To enable the comparison between the two-channel structures, $b_{1}=b_{2}=b$ is assumed.

The manufacturer's expected profits in a dual-channel structure and single-channel structure are $\Pi_{\mathrm{m} \mathrm{B}}^{* \mathrm{NS}}=$ $\left(a^{2}\left(e^{2}(-1+\lambda)^{2}-4 b e(-1+\lambda) \lambda+b^{2}\left(1-2 \lambda+3 \lambda^{2}\right)\right)+\left(b^{2}-e^{2}\right)\left(-e^{2}-\right.\right.$ $\left.\left.2 b e \rho+b^{2}\left(2+\rho^{2}\right)\right) \sigma^{2}\right) / 8\left(b^{3}-b e^{2}\right)$ and $\Pi_{\mathrm{m}_{-} \mathrm{R}}^{* \mathrm{NS}}=\left(a^{2}+b^{2} \rho^{2} \sigma^{2}\right) / 8 b$, respectively. define

With $\Delta=\Pi_{\mathrm{m} \_\mathrm{B}}^{* \mathrm{NS}}-\Pi_{\mathrm{m} \_\mathrm{R}}^{* \mathrm{NS}}, \Delta>0$, and $T=T_{1}+T_{2}>0$, we

$$
\begin{aligned}
T & =a^{2}\left(4 b e(1-\lambda) \lambda-b^{2} \lambda(2-3 \lambda)\right. \\
& \left.+e^{2}\left(2-2 \lambda+\lambda^{2}\right)\right)+\left(b^{2}-e^{2}\right)\left(2 b^{2}-e^{2}-2 b e \rho\right) \\
& \cdot \sigma^{2}, \\
T_{1} & =a^{2}\left(4 b e(1-\lambda) \lambda-b^{2} \lambda(2-3 \lambda)\right. \\
& \left.+e^{2}\left(2-2 \lambda+\lambda^{2}\right)\right), \\
T_{2} & =\left(b^{2}-e^{2}\right)\left(2 b^{2}-e^{2}-2 b e \rho\right) \sigma^{2} .
\end{aligned}
$$

So far we split the profit comparison $T$ into two parts. $T_{1}$ is the part without cost fluctuation, which is equal to the 
profit comparison when $\sigma^{2}=0 . T_{2}$ is the part caused by cost uncertainty. To facilitate our discussion, we will first analyze the profit comparison in a deterministic situation, and then we add the part introduced by uncertainty.

In a deterministic cost situation, we have the following: $T_{1}=a^{2} e^{2}\left[\lambda(3 \lambda-2)(b / e)^{2}+4(1-\lambda) \lambda(b / e)+\left(\lambda^{2}-2 \lambda+2\right)\right]$, due to $b>e$ and $0<\lambda<1$. Proposition 8 is obtained as follows.

\section{Proposition 8. In a deterministic cost situation}

(1) if $\lambda>2 / 3$, then $T_{1}>0$;

(2) if $\lambda<2 / 3$, we have that $T_{1}$ first increases in $b / e \in$ $(1,2(1-\lambda) \lambda / \lambda(2-3 \lambda)]$ and then decreases in $b / e \in$ $(2(1-\lambda) \lambda / \lambda(2-3 \lambda),+\infty)$; when $b / e>(-2 \lambda(1-\lambda)-$ $\left.\sqrt{\lambda\left(\lambda^{3}-6 \lambda+4\right)}\right) / \lambda(3 \lambda-2), T_{1}<0$.

To summarize, when $\lambda$ is sufficiently small and $b$ is large relative to $e$, one gets $T_{1}<0$, with the outcome that the manufacturer suffers from adding a direct channel.

According to Proposition 8, when there is no uncertainty in sales cost and consumers have sufficiently high preference on the retail channel, the basic market share of direct channel is quite favorable and the dual-channel structure is beneficial. However, when the consumer's preference for the direct channel is relatively low and the self-price sensitivity is big enough, a dual-channel structure should not be set up. In this environment, the direct channel is not so welcomed and its performance is heavily affected by its sales price.

After introducing cost uncertainty, the profit comparison condition becomes $T=T_{1}+T_{2}>0$. It is not difficult to find that $\rho$ is negatively correlated with $T_{2}$; the smaller the cost correlation is, the bigger $T_{2}$ is. In addition, $\sigma^{2}$ has two-way effects on $T_{2}$; if $\rho<1 / 2$, then $\sigma^{2}$ is positively correlated with $T_{2}$; if $\rho>1 / 2$ and $b / e<\left(\sqrt{\rho^{2}+2}+\rho\right) / 2$, then $\sigma^{2}$ is negatively correlated with $T_{2}$.

Proposition 9. In an uncertain cost situation, under the assumption of $b_{1}=b_{2}=b>e$, one has the following:

(1) If $\lambda>2 / 3$ and $\rho<1 / 2$, then $T>0$ and $T$ is an increasing function of $b / e$.

(2) If $\lambda>2 / 3$ and $\rho>1 / 2$, then $T_{1}>0$ and $T_{2}$ is negative in $b / e \in\left(1,\left(\sqrt{\rho^{2}+2}+\rho\right) / 2\right)$ and negatively correlated with $\sigma^{2} . T$ is an increasing function of b/e. Certainly, when $b / e>\left(\sqrt{\rho^{2}+2}+\rho\right) / 2, T>0$.

(3) If $\lambda<2 / 3$ and $\rho<1 / 2$, then $T_{2}>0$ and positively correlated with $\sigma^{2} . T_{1}$ first increases and then decreases with respect to an increasing value in $b / e$. When $b / e>\left(-2 \lambda(1-\lambda)-\sqrt{\lambda\left(\lambda^{3}-6 \lambda+4\right)}\right) / \lambda(3 \lambda-2)$, $T_{1}<0$. Certainly, when $b / e \in(1,(-2 \lambda(1-\lambda)-$ $\left.\left.\sqrt{\lambda\left(\lambda^{3}-6 \lambda+4\right)}\right) / \lambda(3 \lambda-2)\right), T>0$.

(4) If $\lambda<2 / 3$ and $\rho>1 / 2$, then $T_{1}$ first increases and then decreases with respect to an increasing value in $b / e$, and $T_{2}$ is an increasing function of b/e. Only when the value of $b / e$ is in a certain range, $T>0$. In addition, when $b / e \in\left(\left(\sqrt{\rho^{2}+2}+\rho\right) / 2,(-2 \lambda(1-\lambda)-\right.$ $\left.\left.\sqrt{\lambda\left(\lambda^{3}-6 \lambda+4\right)}\right) / \lambda(3 \lambda-2)\right), T>0$.

In summary, the conditions for the manufacturer to add a direct channel are shown in Theorem 10.

Theorem 10. In the situation with uncertain costs, if the consumers' preference on direct channel $\lambda$ is sufficiently high relative to the retail channel and cost correlation between two channels $\rho$ is relatively low, then the dual-channel structure is beneficial for the manufacturer. In this scenario, when the selfprice sensitivity relative to cross-price sensitivity b/e increases, the profit difference $\Delta$ between the two channels also increases. In other scenarios, the direction of the effect of b/e on $\Delta$ is uncertain and is determined by $\lambda$ and $\rho$. In addition, the cost correlation coefficient $\rho$ between two channels is negatively related with the profit difference $\Delta$. The fluctuation degree $\sigma^{2}$ has an uncertain effect on $\Delta$. Specifically, when the cost correlation $\rho$ is relatively low, $\Delta$ increases as $\sigma^{2}$ becomes bigger.

5.2. Discussion of Channel Choice. Theorem 10 above provides some very interesting results. Intuitively, when the cost correlation between the two channels is higher, it seems more likely for the manufacturer to own a dual-channel structure, since the manufacturer already has a disadvantage because of cost information leakage. In addition, the cost dependency relationship will make the manufacturer obtain more information on the retailer's cost. We find that the cost correlation is positively related with the manufacturer's profit, which further substantiates this kind of analysis. In actuality, the above analysis holds true for a dual-channel structure or single-channel structure. However, with respect to channel choice, our study has a counterintuitive result: when the cost correlation becomes higher, it is less likely for the manufacturer to add a direct channel. This is because a high cost correlation means that the manufacturer can predict the retail cost more accurately based on its own direct sales cost. Then the manufacturer's pricing strategy can be tailored more for the retailer. The price competition between the two channels becomes more severe, which to some degree hurts the manufacturer's total profit with a two-channel structure. When the cost correlation is low, the manufacturer will not obtain too much information on the retailer's cost, and thus the competitive influence of the direct channel on the retail channel will be weakened. This scenario brings a favorable environment for the manufacturer to pursue higher profits with a dual-channel structure.

When the consumers' preference on direct channel $\lambda$ is relatively high and the cost correlation $\rho$ is sufficiently low, the manufacturer obtains more profit from the dual-channel structure. At the same time, if the self-price sensitivity is relatively high compared with the cross-price sensitivity, the advantage of adding a direct channel improves because the direct channel's demand is relatively less affected by the retail channel. 

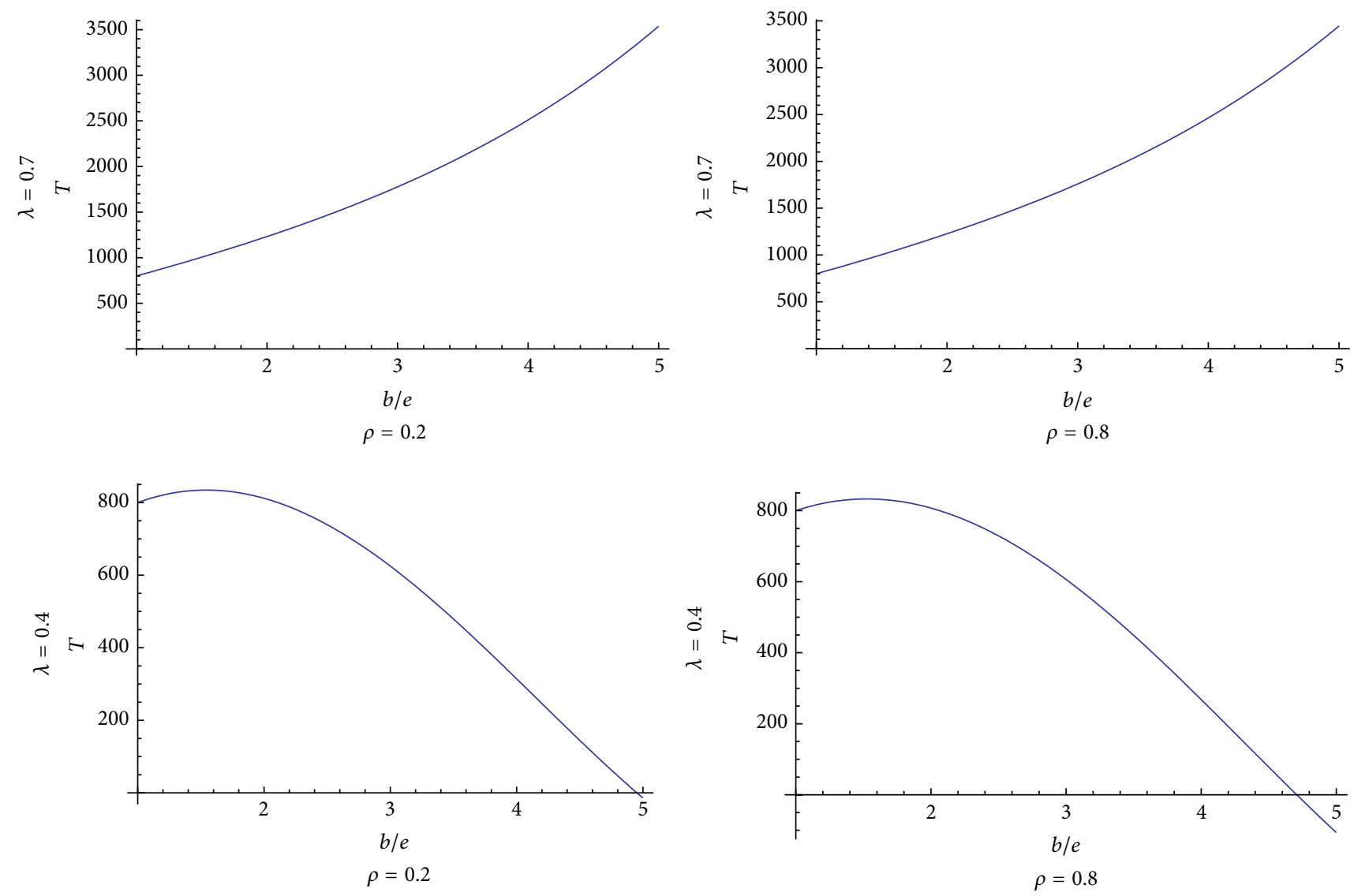

FIGURE 1: The profit difference between two channels ( $\rho=(0.2,0.8), \lambda=(0.4,0.7), a=20$, and $\sigma=0.8)$.

The results of our numerical simulations showing the effect of the relative degree of self-price sensitivity on channel choice under a variety of combinations of $\lambda$ and $\rho$ are provided in Figure 1. Obviously, the effect of relative self-price sensitivity on the profit difference depends on the specific scenarios.

With respect to cost fluctuation, its effect on channel choice is uncertain and dependent on the scenario tested. Specifically, when the cost correlation between two channels is weak and costs are fluctuating sharply, the manufacturer's information acquisition on retail sales cost decreases, and the competitive influence from a direct channel is limited for the retailer. At the same time, adding a new direct channel will play a role of risk pooling, just like the saying "Don't put all your eggs in one basket." Thus it is more likely for the manufacturer to open up a new direct channel.

\section{Conclusion}

In practice, sales costs are usually uncertain and affected by several factors. At the same time, with the rapid development of e-commerce, the form of dual-channel structure is quite common in a supply chain. Our paper focuses on information sharing in a dual-channel supply chain consisting of one manufacturer and one retailer. Assuming that the retail sale cost and direct sale cost are random variables with a general distribution, the paper builds a Bertrand competition model between two channels in a Stackelberg game.

The retailer's private information on retail sales cost is found to be valuable for the manufacturer in both single-channel and dual-channel structures. However, the retailer is not willing to share private information because the manufacturer will use the data to squeeze the retailer's profit by using a stricter pricing strategy. This is reflected in the results that show the manufacturer's profit improving when the cost correlation between two channels increases.

Our study finds that only when the cost correlation between two channels is relatively low, the advantage of the dual-channel structure is enhanced. This is because a low cost correlation means that the manufacturer will not obtain much information on the retailer's cost according to the cost dependency, and the competitive influence of the direct channel on retail channel will be weakened. As such this is a favorable environment for the manufacturer to get a great whole profit using the dual channels. When the cost correlation is very high, the manufacturer can predict the retail cost more accurately. This will lead to a stricter pricing strategy and eventually result in intensive price competition between the two channels. In practice, when the direct channel and retail channel become more independent, the 
price competition between the two channels can be relieved to some degree. The outcome is that a dual-channel strategy could be considered.

The condition for the manufacturer to add a direct channel is affected by many factors including market preference, the cost correlation degree, price sensitivities, and cost fluctuation. Specifically, if the consumers' preference on direct channel is sufficiently high and the cost correlation is relatively low, which creates a condition with potential market share and relative independence for the direct channel, the manufacturer can benefit from both channels and obtain more profit from the dual-channel structure. At the same time, the bigger the self-price sensitivity relative degree is, the higher the manufacturer's added profit from dualchannel structure is. Also, the results show that when the cost correlation between two channels is very weak, the cost fluctuation improves the advantage of adding a direct channel. From these, we can see that market fluctuation sometimes will stimulate a manufacturer to add a direct channel.

The paper can be extended in several directions. As noted earlier, cooperation contract is beyond the scope of our research. Future research could introduce cooperation contracts into the model. We assume the retailer is only a price taker in our research. By incorporating bargaining power for the retailers, we could see some interesting results. In addition, multiple retailers could be introduced to examine the effect of competition between retailers on channel choice.

\section{Appendix}

Proof of Lemma 1. Assume the correlation coefficient between $c_{\mathrm{d}}$ and $c_{\mathrm{r}}$ is $\rho$ :

$$
\begin{aligned}
& \operatorname{Cov}\left(c_{\mathrm{d}}, c_{\mathrm{r}}\right)=\rho \sigma^{2}=E\left[\begin{array}{ll}
c_{\mathrm{d}} & c_{\mathrm{r}}
\end{array}\right]-E\left[c_{\mathrm{d}}\right] E\left[c_{\mathrm{r}}\right]
\end{aligned}
$$

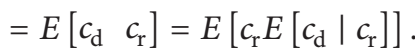

According to our assumption, $E\left[c_{\mathrm{d}} \mid c_{\mathrm{r}}\right]=\alpha_{1}+\alpha_{2} c_{\mathrm{r}}$. Consider

$$
\begin{aligned}
E\left[c_{\mathrm{r}} E\left[c_{\mathrm{d}} \mid c_{\mathrm{r}}\right]\right] & =E\left[c_{\mathrm{r}}\left(\alpha_{1}+\alpha_{2} c_{\mathrm{r}}\right)\right] \\
& =E\left[c_{\mathrm{r}} \alpha_{1}\right]+E\left[\alpha_{2} c_{\mathrm{r}}^{2}\right]=\alpha_{2} E\left[c_{\mathrm{r}}^{2}\right] \\
& =\alpha_{2}\left(\sigma^{2}+\left(E\left[c_{\mathrm{r}}\right]\right)^{2}\right)=\alpha_{2} \sigma^{2}
\end{aligned}
$$

Thus, we have $\alpha_{2}=\rho$.

Because $E\left[E\left[c_{\mathrm{d}} \mid c_{\mathrm{r}}\right]\right]=E\left[a_{1}+a_{2} c_{\mathrm{r}}\right]=a_{1}$ and $E\left[E\left[c_{\mathrm{d}} \mid\right.\right.$ $\left.\left.c_{\mathrm{r}}\right]\right]=E\left[c_{\mathrm{d}}\right]=0$, we obtain $\alpha_{1}=0$.

So far, we proved that $E\left[c_{\mathrm{d}} \mid c_{\mathrm{r}}\right]=\rho c_{\mathrm{r}}$. Similarly, $E\left[c_{\mathrm{r}} \mid\right.$ $\left.c_{\mathrm{d}}\right]=\rho c_{\mathrm{d}}$ can be proved.

Proof of Proposition 2. We have obtained the following retailer's best response function of retail price in stage $2: p_{\mathrm{r}}=$ $\left(a(1-\lambda)+\left(\omega+c_{\mathrm{r}}\right) b_{2}+e p_{\mathrm{d}}\right) / 2 b_{2}$.
Substituting the retailer's best response function into the manufacturer's conditional expected profit in stage 1 , we have

$$
\begin{aligned}
& E\left[\pi_{\mathrm{m}} \mid c_{\mathrm{d}}\right]=\left(p_{\mathrm{d}}-c_{\mathrm{d}}\right)\left(\lambda a-b_{1} p_{\mathrm{d}}\right. \\
& \left.+e \frac{a(1-\lambda)+\left(\omega+\rho c_{\mathrm{d}}\right) b_{2}+e p_{\mathrm{d}}}{2 b_{2}}\right) \\
& +\omega\left((1-\lambda) a-b_{2} \frac{a(1-\lambda)+\left(\omega+\rho c_{\mathrm{d}}\right) b_{2}+e p_{\mathrm{d}}}{2 b_{2}}\right. \\
& \left.+e p_{\mathrm{d}}\right)
\end{aligned}
$$

and then we take the first-order derivative with respect to $p_{\mathrm{d}}$ and $\omega$ :

$$
\begin{aligned}
& \frac{\partial E\left[\pi_{\mathrm{m}} \mid c_{\mathrm{d}}\right]}{\partial p_{\mathrm{d}}} \\
& =a \lambda+\frac{e \omega}{2}-b_{1} p_{\mathrm{d}}+\left(-b_{1}+\frac{e^{2}}{2 b_{2}}\right)\left(-c_{\mathrm{d}}+p_{\mathrm{d}}\right) \\
& \quad+\frac{e\left(a(1-\lambda)+b_{2}\left(\omega+\rho c_{\mathrm{d}}\right)+e p_{\mathrm{d}}\right)}{2 b_{2}}, \\
& \frac{\partial E\left[\pi_{\mathrm{m}} \mid c_{\mathrm{d}}\right]}{\partial \omega} \\
& \quad a(1-\lambda)-\frac{\omega b_{2}}{2}+e p_{\mathrm{d}}+\frac{1}{2} e\left(-c_{\mathrm{d}}+p_{\mathrm{d}}\right) \\
& \quad+\frac{1}{2}\left(-a(1-\lambda)-b_{2}\left(\omega+\rho c_{\mathrm{d}}\right)-e p_{\mathrm{d}}\right) .
\end{aligned}
$$

Next, we combine the above first-order conditions and solve $\partial E\left[\pi_{\mathrm{m}} \mid c_{\mathrm{d}}\right] / \partial p_{\mathrm{d}}=0$ and $\partial E\left[\pi_{\mathrm{m}} \mid c_{\mathrm{d}}\right] / \partial \omega=0$ simultaneously. Note that the two equations are linear functions with respect to $p_{\mathrm{d}}$ and $\omega$, so we have a unique equilibrium solution:

$$
\begin{aligned}
& \omega^{*}=\frac{-e\left(a \lambda+e \rho c_{\mathrm{d}}\right)+b_{1}\left(a(-1+\lambda)+\rho b_{2} c_{\mathrm{d}}\right)}{2\left(e^{2}-b_{1} b_{2}\right)}, \\
& p_{\mathrm{d}}^{*}=\frac{e\left(a(-1+\lambda)+e c_{\mathrm{d}}\right)-b_{2}\left(a \lambda+b_{1} c_{\mathrm{d}}\right)}{2\left(e^{2}-b_{1} b_{2}\right)} .
\end{aligned}
$$

With the above equilibrium solution, we can then compute the conditional expected profits and expected profits of the manufacturer and retailer in the equilibrium condition.

Proof of Proposition 3. In stage 2, the retailer's best response function of retail price is as follows:

$$
p_{\mathrm{r}}=\frac{a(1-\lambda)+\left(\omega+c_{\mathrm{r}}\right) b_{2}+e p_{\mathrm{d}}}{2 b_{2}}
$$


Substituting the retailer's best response function into the manufacturer's conditional expected profit in stage 1 , we have

$$
\begin{aligned}
& E\left[\pi_{\mathrm{m}} \mid c_{\mathrm{d}}, c_{\mathrm{r}}\right]=\left(p_{\mathrm{d}}-c_{\mathrm{d}}\right)\left(\lambda a-b_{1} p_{\mathrm{d}}\right. \\
& \left.+e \frac{a(1-\lambda)+\left(\omega+c_{\mathrm{r}}\right) b_{2}+e p_{\mathrm{d}}}{2 b_{2}}\right)+\omega((1-\lambda) a \\
& \left.-b_{2} \frac{a(1-\lambda)+\left(\omega+c_{\mathrm{r}}\right) b_{2}+e p_{\mathrm{d}}}{2 b_{2}}+e p_{\mathrm{d}}\right)
\end{aligned}
$$

and then we take the first-order derivative with respect to $p_{\mathrm{d}}$ and $\omega$ :

$$
\begin{aligned}
& \frac{\partial E\left[\pi_{\mathrm{m}} \mid c_{\mathrm{d}}, c_{\mathrm{r}}\right]}{\partial p_{\mathrm{d}}} \\
& =a \lambda+\frac{e \omega}{2}-b_{1} p_{\mathrm{d}}+\left(-b_{1}+\frac{e^{2}}{2 b_{2}}\right)\left(-c_{\mathrm{d}}+p_{\mathrm{d}}\right) \\
& +\frac{e\left(a(1-\lambda)+b_{2}\left(\omega+c_{\mathrm{r}}\right)+e p_{\mathrm{d}}\right)}{2 b_{2}}, \\
& \frac{\partial E\left[\pi_{\mathrm{m}} \mid c_{\mathrm{d}}, c_{\mathrm{r}}\right]}{\partial \omega}
\end{aligned}
$$

$$
\begin{gathered}
=a(1-\lambda)-\frac{\omega b_{2}}{2}+e p_{\mathrm{d}}+\frac{1}{2} e\left(-c_{\mathrm{d}}+p_{\mathrm{d}}\right) \\
+\frac{1}{2}\left(-a(1-\lambda)-b_{2}\left(\omega+c_{\mathrm{r}}\right)-e p_{\mathrm{d}}\right) .
\end{gathered}
$$

Next, we combine the above first-order conditions and solve $\partial E\left[\pi_{\mathrm{m}} \mid c_{\mathrm{d}}\right] / \partial p_{\mathrm{d}}=0$ and $\partial E\left[\pi_{\mathrm{m}} \mid c_{\mathrm{d}}\right] / \partial \omega=$ 0 simultaneously. Note that the two equations are linear functions with respect to $p_{\mathrm{d}}$ and $\omega$, so we have a unique equilibrium solution:

$$
\begin{aligned}
& \omega^{*}=\frac{-e\left(a \lambda+e c_{\mathrm{r}}\right)+b_{1}\left(a(-1+\lambda)+b_{2} c_{\mathrm{r}}\right)}{2\left(e^{2}-b_{1} b_{2}\right)}, \\
& p_{\mathrm{d}}^{*}=\frac{e\left(a(-1+\lambda)+e c_{\mathrm{d}}\right)-b_{2}\left(a \lambda+b_{1} c_{\mathrm{d}}\right)}{2\left(e^{2}-b_{1} b_{2}\right)} .
\end{aligned}
$$

With the above equilibrium solution, we can then compute the conditional expected profits and expected profits of the manufacturer and retailer in the equilibrium condition.

Proof of Theorem 4. In the two situations without and with retailer's cost information sharing, the expected profits of the manufacturer are as follows:

$$
\begin{aligned}
& \Pi_{\mathrm{m} \_\mathrm{B}}^{* \mathrm{NS}} \\
& =\frac{\rho^{2} b_{1} b_{2}^{3} \sigma^{2}+e^{2}\left((a-a \lambda)^{2}+e^{2} \sigma^{2}\right)+b_{2}\left((a-a \lambda)^{2} b_{1}-3 b_{1} e^{2} \sigma^{2}+4 e a^{2}\left(\lambda-\lambda^{2}\right)+2 \rho e^{3} \sigma^{2}\right)+b_{2}^{2}\left(2 a^{2} \lambda^{2}-e^{2} \rho^{2} \sigma^{2}+2 b_{1}^{2} \sigma^{2}-2 b_{1} e \rho \sigma^{2}\right)}{8 b_{2}\left(b_{1} b_{2}-e^{2}\right)}, \\
& \Pi_{\mathrm{m} \_\mathrm{B}}^{* \mathrm{~S}} \\
& =\frac{e^{2}\left((a-a \lambda)^{2}+e^{2} \sigma^{2}\right)+b_{1} b_{2}^{3} \sigma^{2}+b_{2}\left((a-a \lambda)^{2} b_{1}-3 b_{1} e^{2} \sigma^{2}+4 e a^{2}\left(\lambda-\lambda^{2}\right)+2 \rho e^{3} \sigma^{2}\right)+b_{2}^{2}\left(2 a^{2} \lambda^{2}+2 b_{1}^{2} \sigma^{2}-e^{2} \sigma^{2}-2 b_{1} e \rho \sigma^{2}\right)}{8 b_{2}\left(b_{1} b_{2}-e^{2}\right)} .
\end{aligned}
$$

By comparison, we have $\Pi_{\mathrm{m} \_\mathrm{B}}^{* \mathrm{~S}}-\Pi_{\mathrm{m} \_\mathrm{B}}^{* \mathrm{NS}}=(1 / 8)(1-$ $\left.\rho^{2}\right) \sigma^{2} b_{2}>0$, and the manufacturer's profit increases after retailer's information sharing.

In the two situations without and with retailer's cost information sharing, the retailer's expected profits are as follows:

$$
\begin{aligned}
\Pi_{\mathrm{r}_{-} \mathrm{B}}^{* \mathrm{NS}} & \\
= & \frac{a^{2}(1-\lambda)^{2}}{16 b_{2}} \\
& +\frac{\sigma^{2}}{16 b_{2}}\left(\left(e+\rho b_{2}\right)^{2}+4 b_{2}^{2}-4\left(e+\rho b_{2}\right) b_{2} \rho\right), \\
\Pi_{\mathrm{r} \_\mathrm{B}}^{* \mathrm{~S}} & =\frac{a^{2}(1-\lambda)^{2}}{16 b_{2}}+\frac{\sigma^{2}}{16 b_{2}}\left(e^{2}+b_{2}^{2}-2 e b_{2} \rho\right) .
\end{aligned}
$$

By comparison, we have $\Pi_{\mathrm{r}_{-} \mathrm{B}}^{* \mathrm{~S}}-\Pi_{\mathrm{r}_{-} \mathrm{B}}^{* \mathrm{NS}}=-(3 / 16)(1-$ $\left.\rho^{2}\right) \sigma^{2} b_{2}<0$; the retailer's profit decreases after sharing information.

Proof of Theorem 7. In a single retail channel structure, the manufacturer's expected profits without and with retailer's cost information sharing are as follows:

$$
\begin{aligned}
& \Pi_{\mathrm{m} \_\mathrm{R}}^{* \mathrm{NS}}=\frac{a^{2}+b^{2} \rho^{2} \sigma^{2}}{8 b}, \\
& \Pi_{\mathrm{m} \_\mathrm{R}}^{* \mathrm{~S}}=\frac{a^{2}+b^{2} \sigma^{2}}{8 b} .
\end{aligned}
$$

By comparison, we have $\Pi_{\mathrm{m}_{\mathrm{R}} \mathrm{R}}^{* \mathrm{~S}}-\Pi_{\mathrm{m} \_\mathrm{R}}^{* \mathrm{NS}}=(1 / 8) b(1-$ $\left.\rho^{2}\right) \sigma^{2}>0$, and the manufacturer's profit increases after retailer's information sharing. 
In a single retail channel structure, the retailer's expected profits without and with sharing cost information are as follows:

$$
\begin{aligned}
& \Pi_{\mathrm{r}_{-} \mathrm{R}}^{* \mathrm{NS}}=\frac{a^{2}+\left(4-3 \rho^{2}\right) b^{2} \sigma^{2}}{16 b}, \\
& \Pi_{\mathrm{r}-\mathrm{R}}^{* \mathrm{~S}}=\frac{a^{2}+b^{2} \sigma^{2}}{16 b} .
\end{aligned}
$$

By comparison, we have $\Pi_{\mathrm{r}_{-} \mathrm{R}}^{* \mathrm{~S}}-\Pi_{\mathrm{r}_{-} \mathrm{R}}^{* \mathrm{NS}}=-(3 / 16) b(1-$ $\left.\rho^{2}\right) \sigma^{2}<0$, and the retailer's profit decreases after sharing information.

\section{Abbreviations}

$D_{\mathrm{d}}$ : Demand function in the direct channel

$D_{\mathrm{r}}$ : Demand function in the retail channel

$D$ : Demand function in a single-channel structure

a: Basic demand

$\lambda$ : The proportion of basic market demand which goes to the direct channel

$p_{\mathrm{d}}$ : Sale price in the direct channel

$p_{\mathrm{r}}$ : Sale price in the retail channel

$b_{1}$ : The direct channel's own price sensitivity

$b_{2}$ : The retail channel's own price sensitivity

$b$ : Price sensitivity in a single-channel structure

$e$ : Cross-price sensitivity

$c_{\mathrm{d}}$ : The marginal cost in the manufacturer direct sales

$c_{\mathrm{r}}$ : The marginal costs in the retailer's sales

$\rho$ : The correlation coefficient between sale costs in two channels

$\omega$ : The manufacturer's wholesale price

$\pi_{\mathrm{m}}$ : The manufacturer's profit

$\pi_{\mathrm{r}}$ : The retailer's profit.

\section{Competing Interests}

The authors declare that they have no competing interests.

\section{Acknowledgments}

This study has been supported by the Science Foundation of China University of Petroleum, Beijing (nos. 2462014YJRC026, 2462015YQ1403) and Humanities and Social Sciences Youth Foundation of the Ministry of Education of China (Grant no. 15YJC630075).

\section{References}

[1] R. Berner, "Watch out: best buy and circuit city. Wal-Mart is attacking their business model by offering lower-cost warranties," Business Week, vol. 11, pp. 46-48, 2005.

[2] B. Hempelmann, "Optimal franchise contracts with private cost information," International Journal of Industrial Organization, vol. 24, no. 2, pp. 449-465, 2006.
[3] S. Y. Park and H. T. Keh, "Modelling hybrid distribution channels: a game-theoretic analysis," Journal of Retailing and Consumer Services, vol. 10, no. 3, pp. 155-167, 2003.

[4] W.-Y. K. Chiang, D. Chhajed, and J. D. Hess, "Direct marketing, indirect profits: a strategic analysis of dual-channel supplychain design," Management Science, vol. 49, no. 1, pp. 1-20, 2003.

[5] Y. C. Liu and Z. J. Zhang, "Research note-the benefits of personalized pricing in a channel," Marketing Science, vol. 25, no. 1, pp. 97-105, 2006.

[6] A. Dumrongsiri, M. Fan, A. Jain, and K. Moinzadeh, "A supply chain model with direct and retail channels," European Journal of Operational Research, vol. 187, no. 3, pp. 691-718, 2008.

[7] G. G. Cai, "Channel selection and coordination in dual-channel supply chains," Journal of Retailing, vol. 86, no. 1, pp. 22-36, 2010.

[8] W. S. Yoo and E. Lee, "Internet channel entry: a strategic analysis of mixed channel structures," Marketing Science, vol. 30, no. 1, pp. 29-41, 2011.

[9] L. Li, "Cournot oligopoly with information sharing," The RAND Journal of Economics, vol. 16, no. 4, pp. 521-536, 1985.

[10] G. P. Cachon and M. A. Lariviere, "Contracting to assure supply: how to share demand forecasts in a supply chain," Management Science, vol. 47, no. 5, pp. 629-646, 2001.

[11] H. Cavusoglu, H. Cavusoglu, and S. Raghunathan, "Value of and interaction between production postponement and information sharing strategies for supply chain firms," Production and Operations Management, vol. 21, no. 3, pp. 470-488, 2012.

[12] L. Guo, T. Li, and H. Zhang, "Strategic information sharing in competing channels," Production and Operations Management, vol. 23, no. 10, pp. 1719-1731, 2014.

[13] T. Li and H. T. Zhang, "Information sharing in a supply chain with a make-to-stock manufacturer," Omega, vol. 50, pp. 115125,2015

[14] S. Sang, "Supply chain contracts with multiple retailers in a fuzzy demand environment," Mathematical Problems in Engineering, vol. 2013, Article ID 482353, 12 pages, 2013.

[15] N. Shamir, "Strategic information sharing between competing retailers in a supply chain with endogenous wholesale price," International Journal of Production Economics, vol. 136, no. 2, pp. 352-365, 2012.

[16] X. H. Yue and J. Liu, "Demand forecast sharing in a dual-channel supply chain," European Journal of Operational Research, vol. 174, no. 1, pp. 646-667, 2006.

[17] M. Lei, H. Liu, H. Deng, T. Huang, and G. K. Leong, "Demand information sharing and channel choice in a dual-channel supply chain with multiple retailers," International Journal of Production Research, vol. 52, no. 22, pp. 6792-6818, 2014.

[18] S.-J. Ryu, T. Tsukishima, and H. Onari, "A study on evaluation of demand information-sharing methods in supply chain," International Journal of Production Economics, vol. 120, no. 1, pp. 162-175, 2009.

[19] J. H. Wu, X. Zhai, and Z. M. Huang, "Incentives for information sharing in duopoly with capacity constraints," Omega: The International Journal of Management Science, vol. 36, no. 6, pp. 963-975, 2008.

[20] D.-Q. Yao, X. H. Yue, and J. Liu, "Vertical cost information sharing in a supply chain with value-adding retailers," Omega, vol. 36, no. 5, pp. 838-851, 2008.

[21] S. K. Mukhopadhyay, D.-Q. Yao, and X. H. Yue, "Information sharing of value-adding retailer in a mixed channel hi-tech supply chain," Journal of Business Research, vol. 61, no. 9, pp. 950-958, 2008. 
[22] E. Cao, Y. Ma, C. Wan, and M. Lai, "Contracting with asymmetric cost information in a dual-channel supply chain," Operations Research Letters, vol. 41, no. 4, pp. 410-414, 2013.

[23] C. A. Ingene and M. E. Parry, "Is channel coordination all it is cracked up to be?" Journal of Retailing, vol. 76, no. 4, pp. 511-547, 2000.

[24] L. Li and H. T. Zhang, "Confidentiality and information sharing in supply chain coordination," Management Science, vol. 54, no. 8, pp. 1467-1481, 2008.

[25] G. w. Hua, S. y. Wang, and T. C. E. Cheng, "Price and lead time decisions in dual-channel supply chains," European Journal of Operational Research, vol. 205, no. 1, pp. 113-126, 2010.

[26] W. Huang and J. M. Swaminathan, "Introduction of a second channel: implications for pricing and profits," European Journal of Operational Research, vol. 194, no. 1, pp. 258-279, 2009.

[27] B. Li, M. Y. Zhu, Y. S. Jiang, and Z. H. Li, "Pricing policies of a competitive dual-channel green supply chain," Journal of Cleaner Production, vol. 112, part 3, pp. 2029-2042, 2016.

[28] J. S. Raju and A. Roy, "Market information and firm performance," Management Science, vol. 46, no. 8, pp. 1075-1084, 2000.

[29] L. Li, "Information sharing in a supply chain with horizontal competition," Management Science, vol. 48, no. 9, pp. 1196-1212, 2002 . 


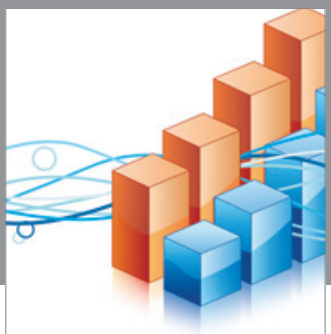

Advances in

Operations Research

vatem alat4

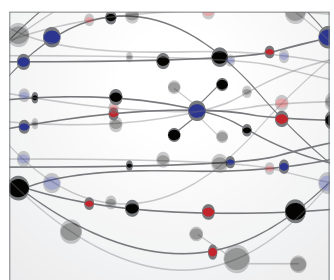

\section{The Scientific} World Journal
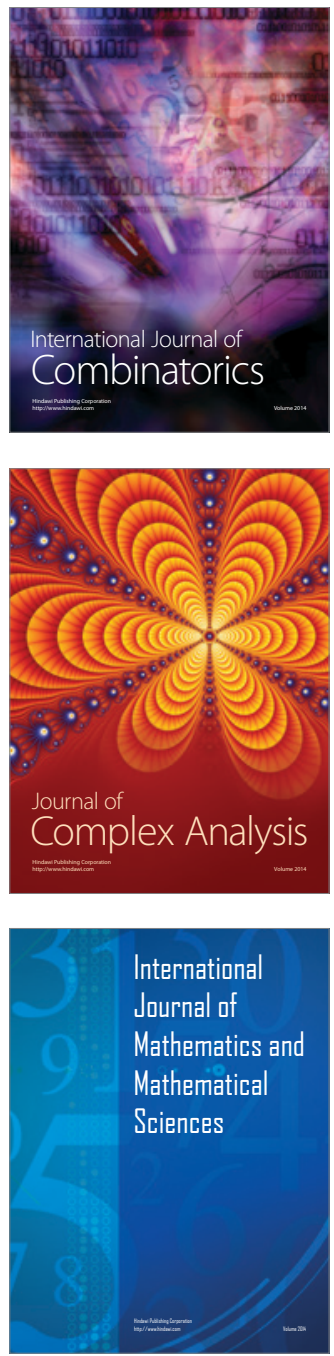
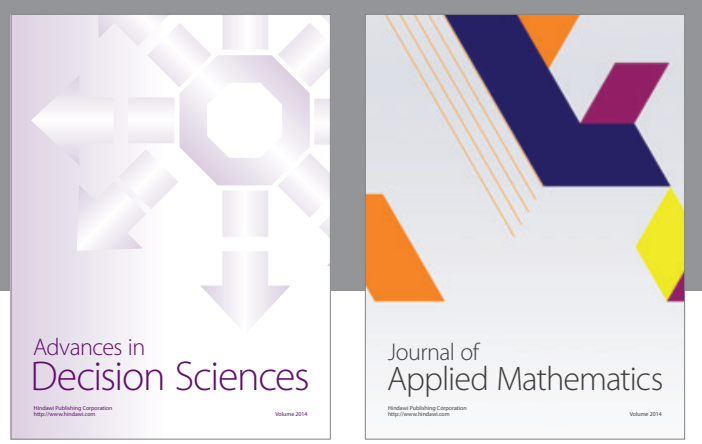

Algebra

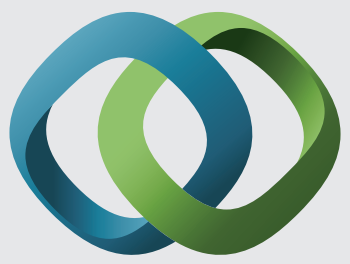

\section{Hindawi}

Submit your manuscripts at

http://www.hindawi.com
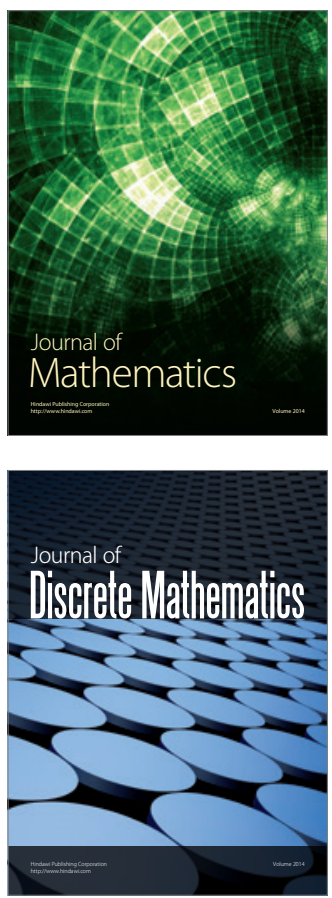

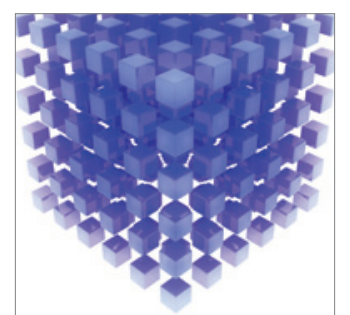

Mathematical Problems in Engineering
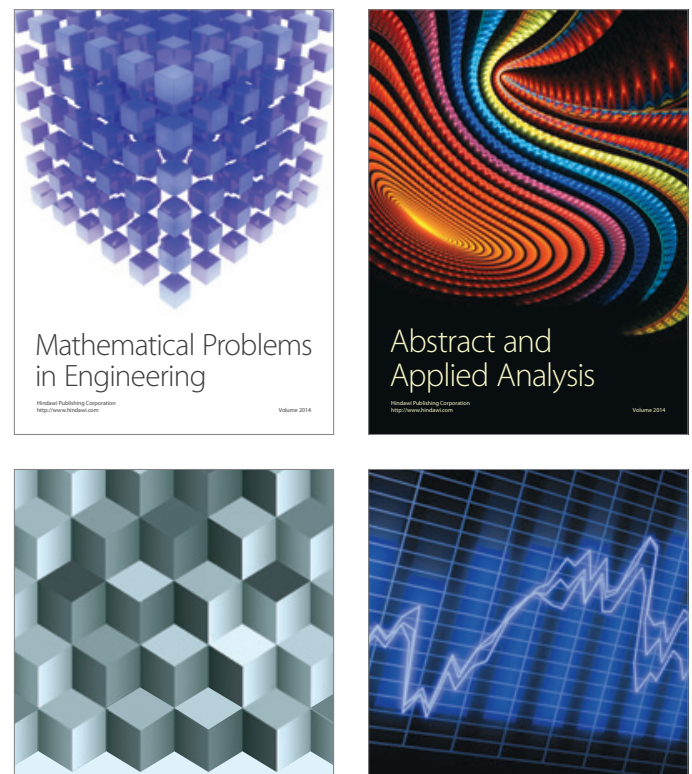

Journal of

Function Spaces

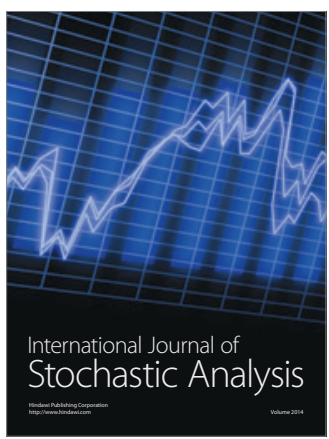

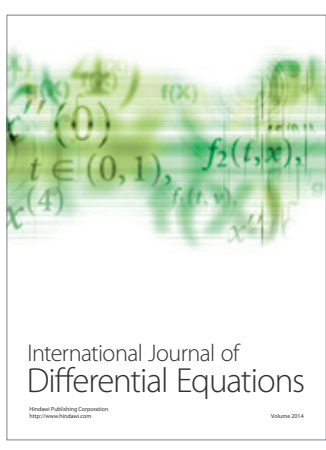
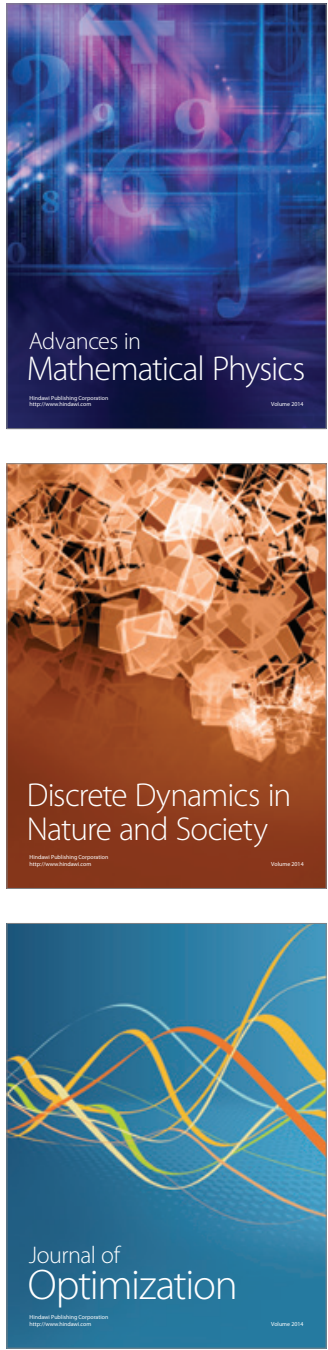